Modern Physics Letters B, Vol. 11, No. 12 (1997) 547-548

(C) World Scientific Publishing Company

\title{
ERRATUM
}

\section{ELASTIC BEHAVIOR AND LATTICE VIBRONICS OF bcc PHASE METALS}

[Mod. Phys. Lett. B, Vol. 11, No. 5 (1997) 209-218]

A. VERMA, M. L. VERMA

and

R. P. S. RATHORE

On p. 215 the following three figures were omitted:

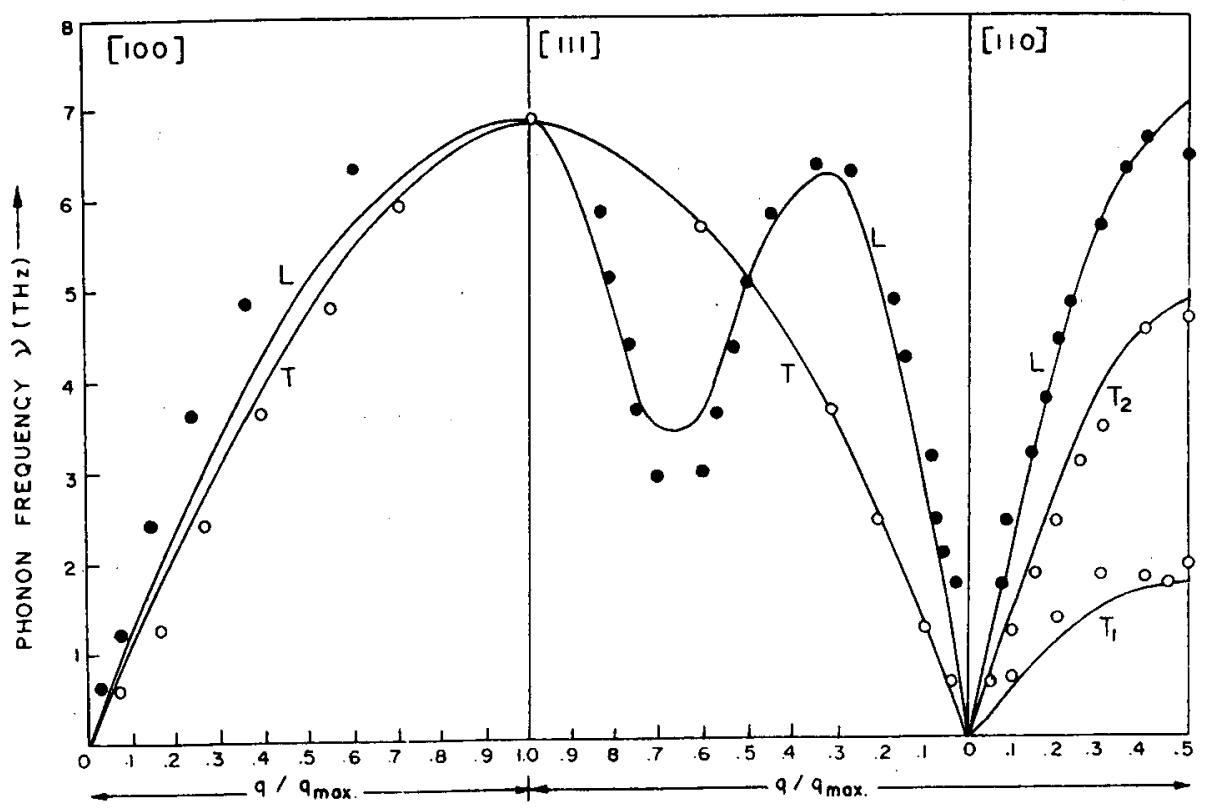

Fig. 1. Phonon dispersion in bcc titanium - Present study; •, ० experimental findings of Petry et al. ${ }^{1}$ 


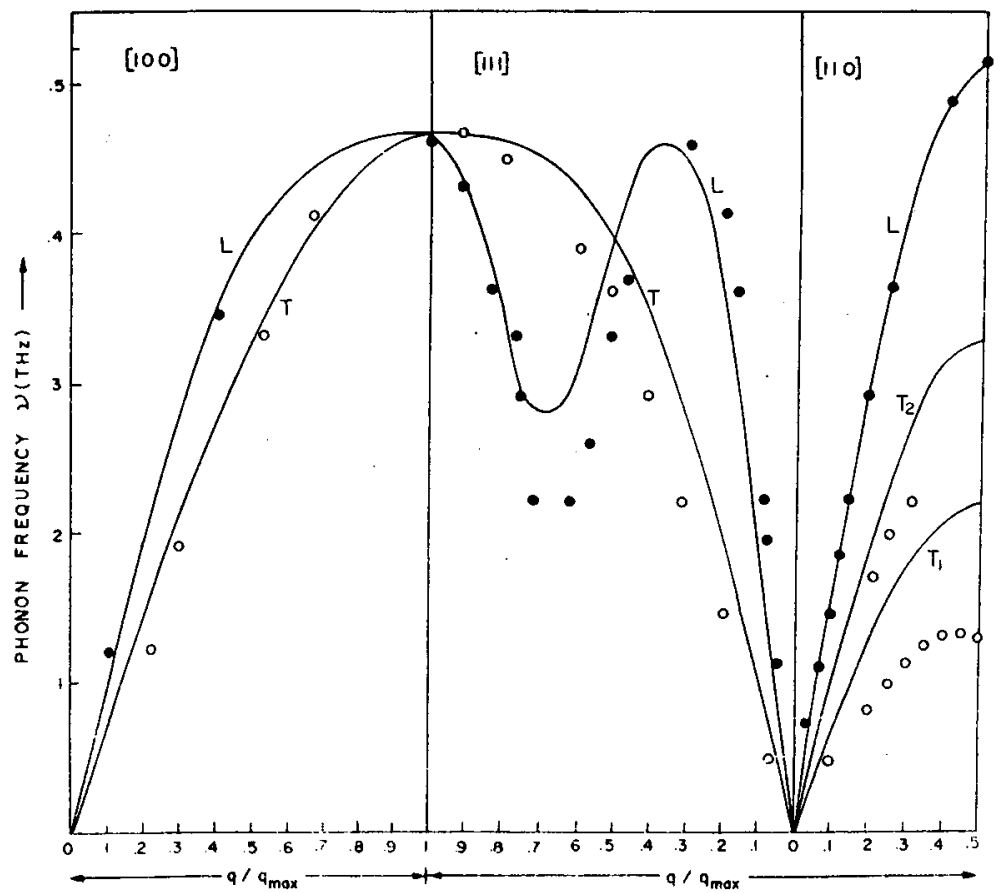

Fig. 2. Phonon dispersion in bcc Zirconium - Present study; $\bullet$,, experimental findings of Heiming et al. ${ }^{2}$

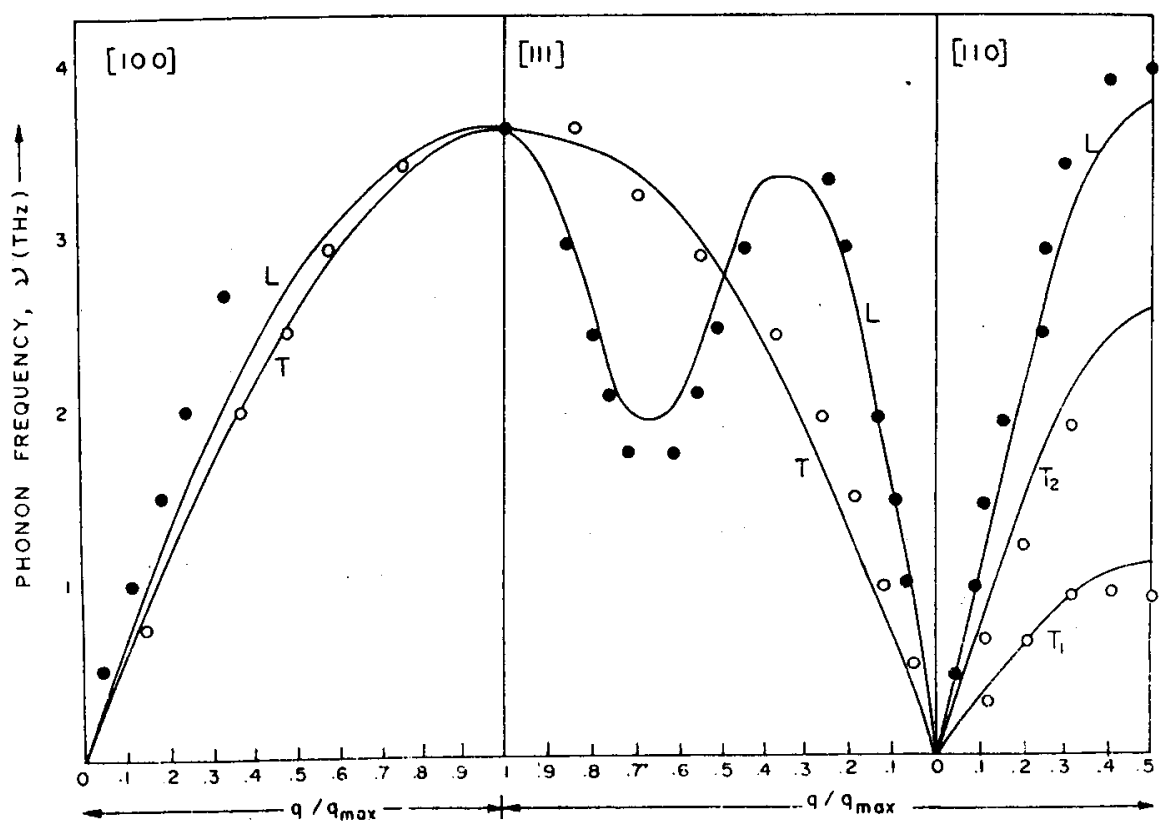

Fig. 3. Phonon dispersion in bcc hafnium - Present study; $\bullet$, ० experimental findings of Trampenau et $a l^{3}$ 